\title{
EFFECT OF SUPPLEMENTATION OF VITAMIN C ON BLOOD GLUCOSE AND GLYCOSYLATED HEMOGLOBIN LEVELS IN EXPERIMENTALLY-INDUCED DIABETIC RABBITS
}

\author{
VIJAYAKRISHNA $\mathbf{P}^{1}$, USHASREE TS ${ }^{2}$, INDIRA $\mathrm{K}^{3}$, AVULA NAVEEN ${ }^{3 *}$, SHIRISHA $\mathbf{S}^{1}$
}

${ }^{1}$ Pharmacovigilance Physician, Vigi Medsafe, Hyderabad, Telangana, India. ${ }^{2}$ Department of Pharmacology, ESIC Medical College, Hyderabad, Telangana, India. ${ }^{3}$ Department of Pharmacology, Government Medical College, Nizamabad, Telangana, India. Email: a.naveen.gmc@gmail.com

Received: 24 March 2020, Revised and Accepted: 24 April 2020

\section{ABSTRACT}

Objectives: Diabetes mellitus (DM) is a spectrum of common metabolic disorders, arising from a variety of pathogenic mechanisms resulting in hyperglycemia that causes chronic micro- and macro-vascular complications. Vitamin C is structurally similar to glucose and can replace it in many chemical reactions and thus is effective in the prevention of non-enzymatic glycosylation of proteins. Hence, the present study taken up to see the effect of supplementation of Vitamin C on blood glucose and glycosylated hemoglobin (HbA1c) along with metformin in experimentally-induced diabetic rabbits.

Methods: Twenty-four adult New Zealand white rabbits (1.5-2.5 kg) were divided into four groups, each containing six rabbits. Group 1: Normal control (distilled water); Group 2: Metformin (23.33 mg/kg) is given orally; Group 3: Metformin (23.33 mg/kg) plus Vitamin C $250 \mathrm{mg}$ are given orally; and Group 4: Metformin (23.33 mg/kg) plus Vitamin C $500 \mathrm{mg}$ are given orally. Animals were treated for 30 days. The blood samples were collected on days 0 and 30 from the marginal ear vein of rabbits for the estimation of blood glucose and HbA1c levels.

Results: Statistically analyzed by ANOVA test followed by post hoc Tukey's test using GraphPad Prism software. Results shown that Vitamin C 500 mg oral supplementation with metformin had very highly significantly reduced HbA1c levels by $40.12 \%(\mathrm{p}=0.0001 * * *)$ and blood glucose levels by $49.12 \%$ $\left(\mathrm{p}=0.0003^{* * *}\right)$, whereas Vitamin C $250 \mathrm{mg}$ oral supplementation with metformin also significantly reduced HbA1c levels by $25.49 \%$ ( $\mathrm{p}=0.0001^{* * *}$ ) and blood glucose levels by $42.95 \%\left(p=0.0026^{* *}\right.$ ) when compared to metformin alone, which reduced HbA1c levels by $22 \%$ ( $\left.p=0.0001 * * *\right)$ and blood glucose levels by $39.58 \%\left(\mathrm{p}=0.0001^{* * *}\right)$.

Conclusion: Oral supplementation of Vitamin C $500 \mathrm{mg} / 250 \mathrm{mg}$ to the metformin was superior in reducing HbA1c levels and blood glucose levels compared to metformin alone in rabbits. Hence, Vitamin C oral supplementation may be helpful in lowering blood glucose levels and HbA1c levels and improving glycemic control in Type $2 \mathrm{DM}$.

Keywords: Alloxan, Blood glucose, Diabetic rabbits, Glycosylated hemoglobin, Metformin, Vitamin C.

(C) 2020 The Authors. Published by Innovare Academic Sciences Pvt Ltd. This is an open access article under the CC BY license (http://creativecommons. org/licenses/by/4. 0/) DOI: http://dx.doi.org/10.22159/ajpcr.2020.v13i6.37617

\section{INTRODUCTION}

Diabetes mellitus (DM) is a spectrum of common metabolic disorders, arising from a variety of pathogenic mechanisms, all resulting in hyperglycemia. The number of individuals with diabetes is rising rapidly throughout the world. Both genetic and environmental factors contribute to its pathogenesis, which involve insufficient insulin secretion, reduced responsiveness to endogenous or exogenous insulin, increased glucose production, and/or abnormalities in fat and protein metabolism. The resulting hyperglycemia may lead to both acute symptoms and metabolic abnormalities [1]. However, the major sources of the morbidity of diabetes are the chronic complications that arise from prolonged hyperglycemia, including retinopathy, neuropathy, nephropathy, and cardiovascular disease [2].

Diabetes is growing alarmingly in India, home to more than 65.1 million people with the disease in 2013, compared to 50.8 million in 2010 , rising to 131.2 million by 2035, according to the International Diabetes Federation $[3,4]$. According to the World Health Organization criteria, the prevalence of known diabetes was $5.6 \%$ and $2.7 \%$ among urban and rural areas, respectively [5].

Ascorbic acid is one of the most effective, powerful antioxidants in biological fluids. Vitamin C scavenges physiologically important reactive oxygen species such as superoxide radical anion, hydrogen peroxide, hydroxyl radical and singlet oxygen, and also reactive nitrogen species [6-8]. It regenerates other small molecule antioxidants such as $\alpha$-tocopherol, reduced glutathione, urate, and $\beta$-carotene from their respective radical species and may, therefore, prevent oxidative damage to biological macromolecules, including DNA, lipids, and proteins [9-12]. Vitamin C is structurally similar to glucose and hence possibly may replace it in many chemical reactions, such as nonenzymatic glycosylation of proteins (Maillard reactions).

Up-to-date, available literature suggests conflicting results related to supplementation of Vitamin $\mathrm{C}$ and improvement in blood glucose level and glycosylated hemoglobin (HbA1c). However, no study has examined the effects of Vitamin C with metformin in the treatment of Type 2 DM, especially on blood glucose levels in animals. Hence, the present study taken up to see the effect of supplementation of Vitamin $\mathrm{C}$ on blood glucose and HbA1c along with metformin in experimentallyinduced diabetic rabbits.

\section{METHODS}

The study was conducted at the Department of Pharmacology, Gandhi Medical College, Hyderabad, after obtaining ethical clearance from the Institutional Animal Ethics Committee.

Twenty-four male albino rabbits were randomized into groups. All rabbits were allowed an 1-week acclimatization period to become accustomed to the laboratory conditions. Rabbits were randomly divided into four groups, each comprising six rabbits. 
Group 1: Normal control (distilled water)

Group 2: Standard drug (metformin - $23.33 \mathrm{mg} / \mathrm{kg} /$ per oral)

Group 3: Test drug - I supplementing standard drug (metformin $23.33 \mathrm{mg} / \mathrm{kg} / \mathrm{po}$ and Vitamin C $250 \mathrm{mg} / \mathrm{po}$ )

Group 4: Test drug - II supplementing standard drug (metformin $23.33 \mathrm{mg} / \mathrm{kg} / \mathrm{po}$ and Vitamin C $500 \mathrm{mg} / \mathrm{po}$ ).

\section{Duration of the study}

The duration of the study was for 45 days, which included 15 days of the diabetic induction period and the next 30 days of the treatment period.

\section{Experimental animal model and study design}

To evaluate the effect of supplementation of Vitamin $\mathrm{C}$ on blood glucose and HbA1c levels, the "Alloxan-induced diabetic rabbit model" was used.

\section{Procedure}

Induction of diabetes

The rabbit was held in a wooden restrainer specially designed for blood collection. Rabbits weighing 1500-2500 g were made diabetic by injecting $100-120 \mathrm{mg} / \mathrm{kg}$ body weight of alloxan monohydrate. Two grams of glucose/kg body weight dissolved in $10 \mathrm{cc}$ of distilled water were administered orally to each rabbit before alloxan injection and $4 \mathrm{ml}$ of $25 \%$ dextrose is administered i.v after alloxan injection to minimize the anticipated hypoglycemia.

The dose of alloxan monohydrate for each rabbit was selected very carefully not only based on the weight but also the general condition of the animal. The required dose was dissolved in $8 \mathrm{cc}$ of distilled water in a sterile glass beaker and was injected into the marginal ear veins by a butterfly needle mounted on a 5-10 cc syringe contrary to the tuberculin syringe method. Eight days after administration of alloxan, the rabbits having a FBS of more than $200 \mathrm{mg} / \mathrm{dl}$ (normal blood glucose levels of rabbits: $100-145 \mathrm{mg} / \mathrm{dl}$ ) were taken as diabetic and employed for further testing $[13,14]$.

\section{RESULTS}

Effect of supplementation of Vitamin C with metformin on blood glucose levels in alloxan-induced diabetic rabbits for 30 days was observed as follows.

\section{DISCUSSION}

Vitamin C, a water-soluble vitamin with antioxidant action, plays an important role in scavenging oxidative free radicals from various tissues [15]. Vitamin C is structurally similar to glucose and possibly can inhibit many chemical reactions such as non-enzymatic glycosylation of proteins (Maillard reactions) by competing with glucose $[16,17]$. High concentration of ascorbic acid can directly inhibit erythrocyte aldose reductase and provide a rationale for the use of oral Vitamin C supplements in diabetes.

Accordingly, based on these properties, the effect of Vitamin $\mathrm{C}$ has been investigated by supplementing with metformin in reducing blood glucose and HbA1c levels in the present study. The present preclinical study evaluated the effect of supplementation of Vitamin $C$ on blood glucose and HbA1c levels in "Alloxan-induced diabetic rabbit model" for of 30 days.

\section{Analysis of blood glucose levels}

Table 1 shows before (day 0) and after (day 30) treatment variations in mean blood glucose levels in each group of rabbits. ANOVA analysis followed by post hoc Tukey's test explains the findings as follows:

- Mean blood glucose levels in the normal control group varied from $113.3 \mathrm{mg} / \mathrm{dl}$ to $117.5 \mathrm{mg} / \mathrm{dl}$ without much variation during the study with a mean percentage reduction being $3.71 \%(\mathrm{p}=0.4317)$.

- Mean blood glucose levels in standard group varied from $263.5 \mathrm{mg} / \mathrm{dl}$ to $159.2 \mathrm{mg} / \mathrm{dl}$, which was statistically very highly significant ( $\mathrm{p}<0.0001^{* * *}$ ), and the mean percentage reduction was $39.58 \%$.

- Mean blood glucose levels in Test 1 group varied from $284.3 \mathrm{mg} / \mathrm{dl}$ to $162.2 \mathrm{mg} / \mathrm{dl}$, which was statistically highly significant $\left(\mathrm{p}=0.0026^{* *}\right)$, and the mean percentage reduction was $42.95 \%$.

- Mean blood glucose levels in Test 2 group varied from $286.0 \mathrm{mg} / \mathrm{dl}$ to $145.5 \mathrm{mg} / \mathrm{dl}$, which was statistically very highly significant $\left(\mathrm{p}=0.0003^{* * *}\right)$, and the mean percentage reduction was $49.12 \%$.

\section{On day 0 (before treatment)}

One-way ANOVA analysis showed that there was a highly significant mean difference ( $\mathrm{p}=0.0013^{* *}$ ) between overall groups. Post hoc Tukey's multiple comparison test showed a highly significant mean difference between the control group and other three groups, whereas no significance between standard, Test 1, and Test 2 groups.

\section{On day 30 (after treatment)}

One-way ANOVA analysis shown that there was no significant mean difference ( $\mathrm{p}=0.2206)$ between overall groups. Post hoc Tukey's multiple comparison tests showed no significance between any of the groups.

The above analysis indicated that supplementation of Vitamin C $250 \mathrm{mg}$ and $500 \mathrm{mg}$ with metformin had improved the blood glucose levels than metformin alone, but not to the significant level.

Table 1: Statistical analysis (ANOVA) showing a comparison of blood glucose levels $(\mathrm{mg} / \mathrm{dl})$ between different groups on day 0 (before treatment) and day 30 (after treatment) followed by between groups Student's t-test

\begin{tabular}{|c|c|c|c|c|}
\hline Samples collected at days & Groups & mean $\pm S D$ & F-value & p-value \\
\hline \multirow[t]{4}{*}{ Day 0 (before treatment) } & Normal control & $113.3 \pm 11.15$ & 7.69 & $0.0013^{* *}$ \\
\hline & Standard & $263.5 \pm 36.24$ & & \\
\hline & Test 1 & $284.3 \pm 113.1$ & & \\
\hline & Test 2 & $286.0 \pm 85.15$ & & \\
\hline \multirow[t]{3}{*}{ Day 30 (after treatment) } & Normal control & $117.5 \pm 09.89$ & 1.601 & 0.2206 \\
\hline & Standard & $159.2 \pm 23.30$ & & \\
\hline & Test 1 & $162.2 \pm 59.21$ & & \\
\hline \multicolumn{5}{|l|}{ Post hoc Tukey's multiple comparison tests } \\
\hline Groups compared & Day 0 & & Day 30 & \\
\hline Control group versus the standard & $5.020 * *$ & & 2.586 & \\
\hline Control group versus Test 1 & $5.717^{* *}$ & & 2.772 & \\
\hline Control group versus Test 2 & $5.772 * *$ & & 1.738 & \\
\hline Standard versus Test 1 & 0.6965 & & 0.1862 & \\
\hline Standard versus Test 2 & 0.7522 & & 0.848 & \\
\hline
\end{tabular}


Analysis of HbA1c levels

Table 2 shows before (day 0 ) and after (day 30 ) treatment variations mean HbA1c levels in each group of rabbits and ANOVA analysis followed by post hoc Tukey's test.

- Mean HbA1c levels in the normal control group varied from 2.18\% to $2.28 \%$ without much variation during the study, and the mean percentage reduction was $4.54 \%(\mathrm{P}=0.7704)$.

- Mean HbA1c levels in standard group varied from $4.97 \%$ to $3.93 \%$, which were statistically very highly significant $\left(P \leq 0.0001^{* * *}\right)$, and the mean percentage reduction was $22 \%$.

- Mean HbA1c levels in Test 1 group varied from 5.07\% to 3.82\%, which were statistically very highly significant $\left(\mathrm{P}<0.0001^{* * *}\right)$, and the mean percentage reduction was $25.49 \%$.

- Mean HbA1c levels in Test 2 group varied from 5.08\% to 3.05\%, which were statistically very highly significant $\left(\mathrm{P}<0.0001^{* * *}\right)$, and the mean percentage reduction was $40.12 \%$.

\section{On day 0 (before treatment)}

One-way ANOVA analysis showed that there was a very highly significant mean difference $\left(\mathrm{P}=0.0001^{* * *}\right)$ between overall groups. Post hoc Tukey's multiple comparison test showed very highly significant mean difference between the control group and other three groups, whereas no significance between standard, Test 1 , and Test 2 groups.

\section{On day 30 (after treatment)}

One-way ANOVA analysis showed that there was a very highly significant mean difference $\left(\mathrm{P}=0.0003^{* * *}\right)$ between overall groups. Post hoc Tukey's multiple comparison test showed very highly significant mean difference between the control group and standard group, highly significant mean difference between standard and Test 2 groups. There is no much difference between standard, test group 1 and similarly test group 1 and 2 .

The above analysis indicated that supplementation of Vitamin C $500 \mathrm{mg}$ with metformin has significantly improved the HbA1c levels than metformin alone, whereas Vitamin C $250 \mathrm{mg}$ with metformin had better efficacy than that of metformin alone.

Bar diagram 1 shows mean blood glucose levels in different groups of rabbits on day 0 and day 30 , as detailed in Table 1 . It indicates that the blood glucose lowering effect in Test 1 and Test 2 groups is better than that of the standard group.

Bar diagram 2 shows percentage reductions of mean blood glucose levels in 30 days. Percentage reduction in Test 2 (49.12\%) is greater than that of standard, whereas percentage reduction in Test 1 (42.95\%), which is most similar to that of standard (39.58\%).
Bar diagram 3 shows mean HbA1c levels in different groups of rabbits on day 0 and day 30 . It indicates that the HbA1c lowering effect in Test 2 is greater than that of standard, whereas in Test 1, it is almost similar to that of standard.

Bar diagram 4 shows percentage reductions of mean HbA1c levels in 30 days. Percentage reduction in Test $2(40.12 \%)$ is significantly greater than that of standard, whereas percentage reduction in Test $1(25.49 \%)$, which is better than that of standard (22\%).

Based on the above findings

- Supplementation of Vitamin C $500 \mathrm{mg}$ with the metformin was superior in reducing HbA1c levels and blood glucose levels compared to metformin only in rabbits.

- Supplementation of Vitamin C $250 \mathrm{mg}$ with the metformin was beneficial in reducing $\mathrm{HbA1c}$ levels and blood glucose levels compared to metformin only in rabbits.

The results of this study are in agreement with previously published data showing betterment in glycemic control with Vitamin C supplementation [18,19]. Another study shown that there is an inverse relationship between Vitamin $\mathrm{C}$ and HbA1c levels indicating that supplementation with Vitamin C improves glycemic control [20] which can be indirectly correlated with the dose of Vitamin $\mathrm{C}$ in the present study.

Kukner et al. study showed that Vitamin C prevented glomerular damage seen in diabetes when combined with Vitamin $\mathrm{E}$ attributing to their antioxidant action. Supplements with Vitamin C increased urinary oxalate levels, but there is no evidence that they produce kidney stones and even up to $10 \mathrm{~g}$; also, they do not exert any toxic or side effects [21].

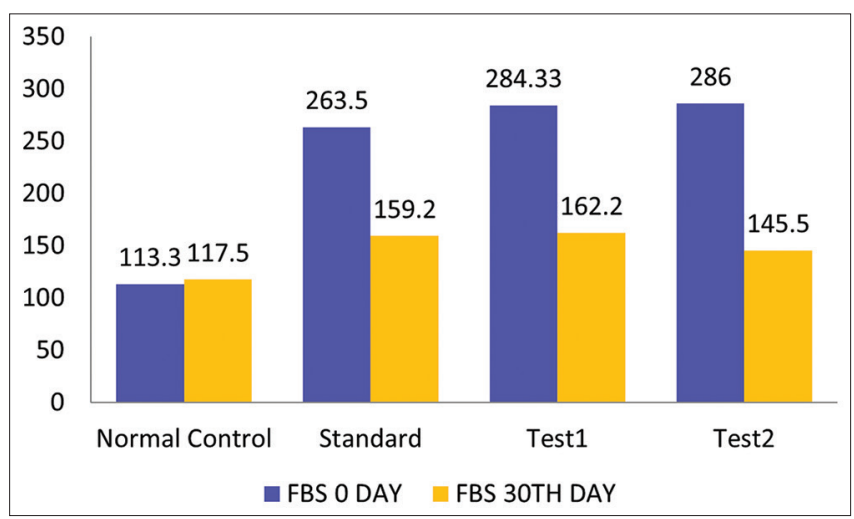

Bar Diagram 1: Day-wise variation in blood glucose levels in various study groups. Y-axis represents blood glucose levels

Table 2: Statistical analysis (ANOVA) showing a comparison of HbA1c levels (\%) between different groups on day 0 (before treatment) and day 30 (after treatment) followed by between groups Student t-test

\begin{tabular}{|c|c|c|c|c|}
\hline Samples collected at days & Groups & mean \pm SD & F-value & p-value \\
\hline \multirow[t]{4}{*}{ Day 0 (before treatment) } & Normal control & $2.183 \pm 0.53$ & 32.22 & $<0.0001^{* * *}$ \\
\hline & Standard & $4.967 \pm 0.46$ & & \\
\hline & Test 1 & $5.067 \pm 0.78$ & & \\
\hline & Test 2 & $5.083 \pm 0.65$ & & \\
\hline \multirow[t]{3}{*}{ Day 30 (after treatment) } & Normal control & $2.28+0.69$ & 9.830 & $0.0003^{* * *}$ \\
\hline & Standard & $3.93+0.29$ & & \\
\hline & Test 1 & $3.82+0.75$ & & \\
\hline
\end{tabular}

Post hoc Tukey's multiple comparison tests

\begin{tabular}{lll}
\hline Groups compared & Day $\mathbf{0}$ & Day $\mathbf{3 0}$ \\
\hline Control group versus standard & $11.06^{* * *}$ & $6.753^{* * *}$ \\
Control group versus Test 1 & $11.45^{* * *}$ & $6.275^{* *}$ \\
Control group versus Test 2 & $11.52^{* * *}$ & 3.138 \\
Standard versus Test 1 & 0.3973 & 0.4775 \\
Standard versus Test 2 & 0.4635 & $5.915^{* *}$ \\
Test 1 versus Test 2 & 0.06621 & 3.138 \\
\hline
\end{tabular}


Abdel-Wahab et al. study showed that the Vitamin C supplementation in obese hyperglycemic (ob/ob) mice significantly reduced glycated hemoglobin, plasma glucose, and insulin concentrations from 26\% to $48 \%$ compared to untreated control ob/ob mice. Vitamin C supplementation also significantly reduced the total insulin content and extent of insulin glycation in the pancreas of ob/ob mice by 42 $45 \%$ and also significantly reduced circulating glycated insulin by $80 \%$. It demonstrates Vitamin $\mathrm{C}$ supplementation that can decrease insulin glycation and amelioration of the obesity-diabetes syndrome in ob/ob mice [22]. Cunningham et al. study showed that Vitamin C supplements

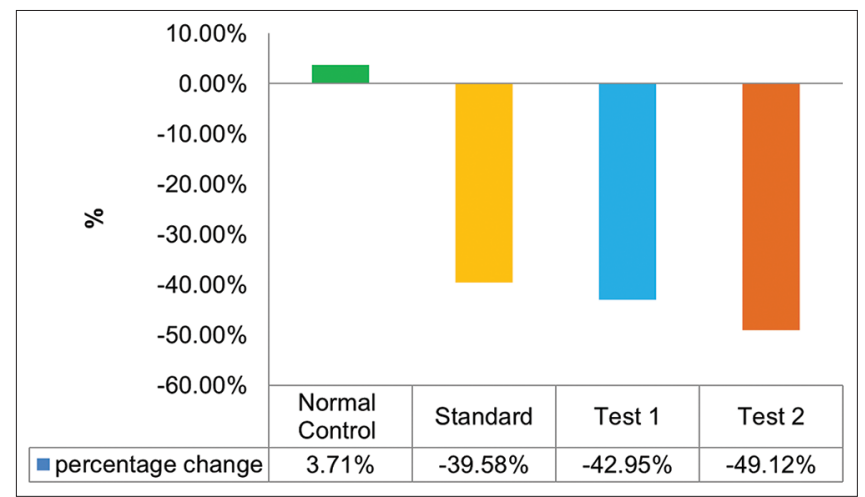

Bar Diagram 2: Percentage reductions of mean blood glucose levels in 30 days for normal control, standard, Test 1, Test 2 groups

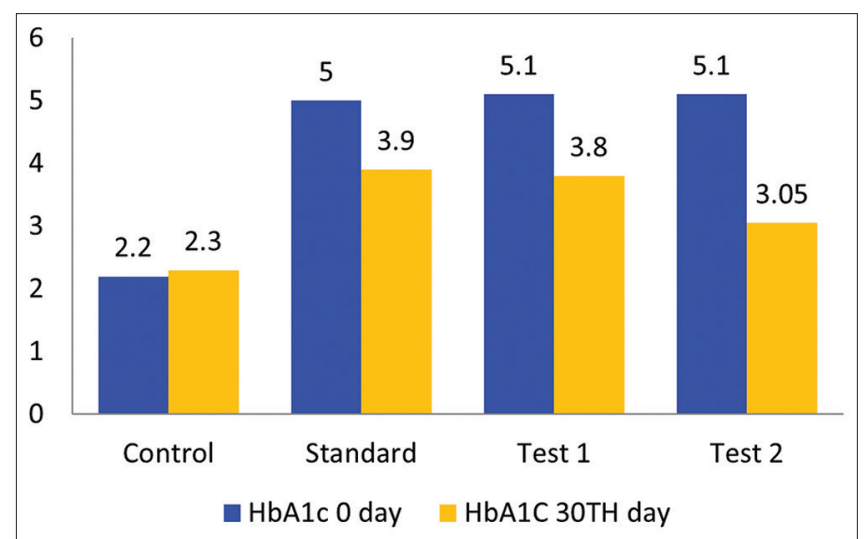

Bar Diagram 3: Before and after treatment variation in glycosylated hemoglobin levels in various groups. Y-axis represents $\mathrm{HbA1c}$ levels in \%

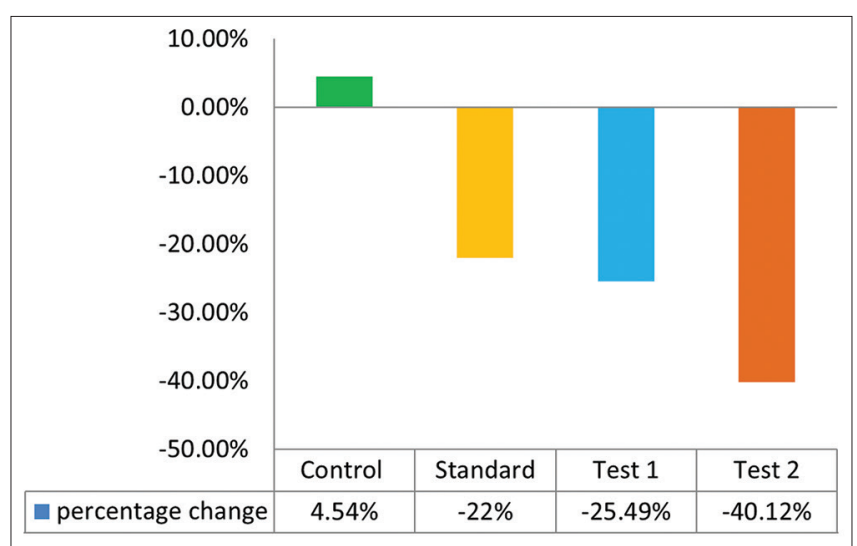

Bar Diagram 4: Percentage reductions of mean HbA1c levels in 30 days for normal control, standard, Test 1, Test 2 groups of both $100 \mathrm{mg}$ and $600 \mathrm{mg}$ had significantly reduced sorbitol accumulation in erythrocytes in IDDM diabetic patients for 58 days. In vitro studies showed that ascorbic acid inhibited aldose reductase activity. Hence suggested, Vitamin $C$ is superior over aldose reductase inhibitors [23].

The exact mechanism by which Vitamin C produces glycemic control is not known. Vitamin $C$ scavenges important reactive oxygen species derived from glucose auto-oxidation, protein glycosylation, and polyol pathway that are involved in the generation of oxidative stress, implicated in the origin of both Types 1 and 2 DM. Vitamin C probably may also inhibit excess glucose uptake by cells of various tissues by competing for insulin. Within cells, Vitamin C possibly may compete with glucose for proteins and thus preventing protein glycation. Thus, Vitamin C supplementation for diabetic subjects may provide a simple means of preventing and ameliorating the complications of diabetes and helpful in maintaining tight glycemic control.

However, studies with a larger sample size and longer follow-up period together with the measurement of plasma Vitamin C levels and other related antioxidant levels are necessary. There is a need for further studies on complicated and uncomplicated Type 2 DM to elucidate the exact role of Vitamin C supplementation in Type 2 DM. Further studies should be done to understand its exact mechanism of action.

\section{CONCLUSION}

Finally, based on the above study, conclusions drawn are as follows:

- Supplementation of Vitamin C $500 \mathrm{mg}$ to the metformin was superior in reducing $\mathrm{HbA1c}$ levels and blood glucose levels compared to metformin alone in rabbits.

- Supplementation of Vitamin C $250 \mathrm{mg}$ to the metformin was beneficial in reducing $\mathrm{HbA} 1 \mathrm{c}$ levels and blood glucose levels compared to metformin alone in rabbits.

Our study would suggest that treatment with Vitamin C with metformin was well tolerated. The cheaper cost and improvement in FBS and HbA1c in Type 2 DM after oral supplementation make it a particularly attractive therapeutic adjuvant in the treatment of Type $2 \mathrm{DM}$.

\section{ACKNOWLEDGMENT}

We would like to thank our Head of the Department Dr. Usha Shree and Professor Dr. Indira for their constant support and scientific inputs.

\section{AUTHORS' CONTRIBUTIONS}

Dr. P. Vijayakrishna raised the idea, designed the study, and participated in statistical analysis, Dr. A. Naveen drafted the manuscript; Dr. K. Indira participated in the study conception and manuscript revision; Dr. S. Shirisha involved in data collection and statistical analysis.

\section{CONFLICTS OF INTEREST}

All authors have none to declare.

\section{AUTHORS' FUNDING}

Self.

\section{REFERENCES}

1. Powers AC, D'Alessio D. Endocrine pancreas and pharmacotherapy of diabetes mellitus and hypoglycemia. In: Goodman and Gilman's the Pharmacological Basis of Therapeutics. 12 ${ }^{\text {th }}$ ed. New York, United States: McGraw-Hill Education; 2011. p. 1237-74.

2. Vinson JA, Howard TB $3^{\text {rd }}$. Inhibition of protein glycation and advanced glycation end products by ascorbic acid and other vitamins and nutrients. J Nutr Biochem 1996;7:659-63.

3. Buse JB, Polonsky KS, Burant CF. Disorders of carbohydrate and metabolism. Type 2 diabetes mellitus. In: Williams Textbook of Endocrinology. 12 $2^{\text {th }}$ ed. Amsterdam, Netherlands: Elsevier; 2011. p. 1371-435. 
4. Cho NH. Diabetes Atlas. $6^{\text {th }}$ ed. Brussels, Belgium: International Diabetes Federation; 2013. Available from: http://www.idf.org/ diabetesatlas/introduction.

5. Ramachandran A, Ma RC, Snehalatha C. Diabetes in Asia. Lancet 2010;375:408-18

6. Hornig DH. Distribution of ascorbic acid, metabolites and analogues in man and animals. Ann N Y Acad Sci 1975;258:103-18.

7. Rose RC. The ascorbate redox potential of tissues: A determinant or indicator of disease. Physiology 1989;4:190-5.

8. Weber P, Bendich A, Schalch W. Vitamin C and human health-a review of recent data relevant to human requirments. Int J Vit Nutr Res 1996;66:19-30.

9. Tannenbaum SR, Wishnok JS, Leaf CD. Inhibition of nitrosamine formation by ascorbic acid. Am J Clin Nutr 1991;53:247-50.

10. Moser U, Weber F. Uptake of ascorbic acid by human granulocytes. Int J Vit Nutr Res 1984;54:47-53.

11. McGowen E, Parenti CM, Hoidal JR, Niewoehner DE. Ascorbic acid content and accumulation by alveolar macrophages from cigarette smokers and non-smokers. J Lab Clin Med 1984;104:127-34

12. Stadtman ER. Ascorbic acid and oxidative inactivation of proteins. Am J Clin Nutr 1991;54:1125-8.

13. Akhtar MS, Athar MA, Yaqub M. Effect of Momordica charantia on blood glucose levels of normal alloxan diabetic rabbits. Planta Med 1981;32:103-5.

14. Puri D, Prabhu KM, Murthy PS. Mechanism of actions of a hypoglycaemic principle isolated in fenugreek seeds. Indian J Physiol Pharmacol 2002;12:46.

15. Al-Deen A, Jawad H, Al-Rikaby AA, Kareem A. Antioxidant, antidiabetic and lipid lowering effects of cinnamon and Vitamin $\mathrm{C}$ in hyperglycemic rabbits. Bas J Vet Res 2011;10:33-48.

16. Kavitha S, Sivaraj R, Ravi D. Antidiabetic activity of Asystasia gangetica (L.) T. Anderson flower extract in streptozotocin induced diabetic rats. Int J Pharm Pharm Sci 2016;8:79-84.

17. Yadav SB, Tripathi V, Singh RK, Pandey HP. Antioxidant activity of Cuscuta reflexa stem. Indian J Pharm Sci 2000;62:477-8.

18. Sridulyakul P, Chakraphan D, Patumraj S. Vitamin C supplementation could reverse diabetes-induced endothelial cell dysfunction in mesenteric microcirculation in STZ-rats. Clin Hemorheol Microcirc 2006;34:315-21.

19. Ardekani MA, Mohiti J, Amirchaghmaghi E, Modarresi M. The effect of Vitamin C supplementation on insulin level, HbAlc and blood glucose in Type 2 diabetic patients. J Kerm Univ Med Sci 2006;11:12-8.

20. Kositsawat J, Freeman VL. Vitamin C and A1c relationship in the national health and nutrition examination survey. J Am Coll Nutr 2011;30:477-83

21. Kukner A, Colakoglu N, Ozoğul C, Naziroglu M, Firat T. The effects of combined Vitamin $\mathrm{C}$ and $\mathrm{E}$ in streptozotocin induced diabetic rat kidney. J Afr Stud Dev 2009;1:29-36.

22. Abdel-Wahab YH, O'Harte FP, Mooney MH, Barnett CR, Flatt PR. Vitamin $\mathrm{C}$ supplementation decrease insulin resistance and improves glucose homeostasis in obese hyperglycemic mice. Metabolism 2002;51:514-7.

23. Cunningham JJ, Meakle PL. Vitamin C an aldolase reductase inhibitor that normalizes erythrocyte sorbitol in insulin dependent diabetes mellitus. J Am Cell Nutr 1994;13:344-5. 